\title{
The association between gestational vitamin $D$ deficiency and preterm birth : A case control study
}

\author{
Case \\ Report \\ Mohamed Ibrahim ${ }^{1}$, Rehab M.Abd Elrahman', Marwa El-Kateb ${ }^{2}$ \\ ${ }^{1}$ Department of Obstetrics \& Gynecology, Faculty of Medicine, Ain-Shams University, Egypt \\ ${ }^{2}$ Department of Obstetrics \& Gynecology, Dar Ismael Maternity Hospital, Alexandria, Egypt
}

\begin{abstract}
Objective: To assess the association between Gestational Vitamin D (VD) deficiency and preterm birth (PTB).

Patients and Methods: This prospective observational nested case control study was conducted at Ain Shams University Maternity Hospital and Dar Ismael Maternity Hospital and sequentially recruited women with singleton pregnancy at 20-28 weeks. Blood samples were collected from all eligible participants and kept frozen until further measurement of maternal VD levels. All enrolled women were followed up till delivery. Cases (PTB) group included woman who delivered before completing 37 weeks of gestation while controls, term birth (TB) group included matched group of those who delivered at or after 37 weeks. The primary study outcome measure was the correlation between VD status and PTB. Results: The final analysis of this study included 40 cases in the PTB group and 40 controls in the TB group. VD deficiency was more prevalent in PTB group $(87.5 \%$ versus $22.5 \%$ in the TB group, $p<0.001)$. PTB group had a statistically significant lower VD levels $(13.34 \pm 7.71 \mathrm{ng} / \mathrm{ml}$ versus $32.91 \pm 18.98 \mathrm{ng} / \mathrm{ml}$ in the TB group, $p<0.001)$ with a moderate positive linear correlation between gestational age at delivery and VD level (Pearson correlation $=0.571, p<0.001$ ). Among the studied maternal outcomes, delivery by cesarean section was more prevalent in PTB group $(62.5 \%$ versus $30.0 \%$ in the TB group, $p=0.004$ ).
\end{abstract}

Conclusion: Gestational VD deficiency was associated with increased risk of PTB and delivery by cesarean section.

Key Words: Cholecalciferol, gestational vitamin D deficiency, preterm birth, preterm labor

Received: $4^{\text {th }}$ July 2019, Accepted: $18^{\text {th }}$ August 2019

Corresponding Author: Rehab M. Abd Elrahman, Department of Obstetrics \& Gynecology, Ain-Shams University Maternity Hospital, Abbasiya Square, Cairo, Egypt, Tel.: 01004992772, E-mail: rehababdulrahman.rm@gmail.com

ISSN: 2090-7625, November 2019, Vol.9, No. 4

\section{INTRODUCTION}

Preterm birth (PTB) is an important cause of perinatal morbidity and mortality. It is a challenging scenario in everyday practice, as it represents $50-75 \%$ of the perinatal mortalities. Clinically, preterm labor (PTL) is diagnosed by the start of regular uterine contractions and cervical changes before completing 37 weeks of gestation with or without rupture of membranes. The rate of PTB ranges between $510 \%$ - in developed countries and up to $25 \%$ in developing countries. Globally, the estimated incidence of PTB is around 6-11\%[1,2].

PTL is not a singular disease; it is a syndrome that has a group of independent reasons. The pathophysiological mechanisms of PTL are still vague. However, there is strong evidence that infection is the most common mechanism leading to early delivery ${ }^{[3,4]}$.

Vitamin D (VD), 1,25-dihydroxycholecalciferol, could prevent PTL by decreasing bacterial infections, as it triggers cathelicidin in the maternal and fetal components of the placenta. Recent studies have revealed a linkage between maternal VD (25-hydroxycholecalciferol) levels and placental antibacterial responsiveness ${ }^{[5,6]}$.

VD deficiency is a growing global clinical issue affecting the health status of various age groups; the pregnant women are among the high-risk categories that can suffer from VD deficiency. The correlation between VD status and PTB has been an area of research interest as VD affects various pathways that could trigger PTL. VD is a secosteroid hormone, synthesized mainly by the dermal structures under the influence of sunlight and transformed to its active form within the hepatic and renal circulations. VD is well recognized for its antioxidant impact, effects on innate and adaptive immunological responses ${ }^{[7-9]}$. VD also affects the reproductive developments in male and female genital systems ${ }^{[10-12]}$. Studies are deficient and considerable research efforts are still required to uncover the correlation 
between VD and the trending obstetric problems such as PTL and PTB ${ }^{[13-17]}$. The current study investigated the correlation between maternal VD status and PTB.

\section{PATIENTS AND METHODS}

This prospective observational nested case control study was conducted at Ain Shams University Maternity Hospital and Dar Ismael Maternity Hospital, between May 2017 and December 2017 and sequentially recruited women with singleton pregnancy at 20-28 weeks. Factors like evidence of maternal and/or fetal abnormalities that can predispose to PTB, prior history of PTB, documented first trimester aneuploidy, concurrent or prior history of incompetent cervix with or without cerclage, acute and/or chronic inflammatory maternal conditions, neoplasms, antepartum hemorrhage, smoking, multifetal gestation, diabetes mellitus, hypertensive disorders and/or intrauterine fetal growth restriction were all considered as the exclusion criteria of the study.

This study was approved by Ain Shams University Ethical Committee. Written informed consent was attained from each participant before conducting any study specific intervention. Blood samples were initially collected from a large cohort and were kept frozen until further measurement of maternal VD (25-hydroxycholecalciferol) levels. All recruited women were followed up every two weeks for any signs or symptoms of PTL. Cases (PTB) group included woman who delivered before completing 37 weeks of gestation; while controls (term birth TB) group included those who delivered at or after 37 weeks and were matched for parity, age, body mass index and other potential confounders.

The gestational age was calculated based on the date of last menstrual period and confirmed by ultrasound scanning (Sono ACE 6000, Medison, South Korea).

Measurement of maternal VD (25-hydroxycholecalciferol) levels was performed for all cases and matched controls using DRG 25(OH) VD total ELISA Kit, EIA-5396 (DRG Instruments GmbH, Germany) which is an enzyme immunoassay for the quantitative in vitro diagnostic measurement of total VD (25-hydroxycholecalciferol), VD2-D3, in serum or plasma samples (EDTA plasma, heparin plasma, citrate plasma). DRG $25(\mathrm{OH})$ VD Total enzyme-linked immunosorbent assay (ELISA) Kit is a solid phase ELISA based on the competitive binding principle. In the first step, samples were pretreated in separate vials with denaturation buffer to extract the analyte, since most circulating $25(\mathrm{OH}) \mathrm{VD}$ is bound to VDBP in vivo. After neutralization, biotinylated 25(OH) VD (enzyme conjugate) and peroxidase-labeled streptavidin (enzyme complex) were added. After mixing, the solution was carefully transferred to the wells of the microtiter plate. Endogenous 25(OH) VD of a patient sample competes with a $25(\mathrm{OH})$ VD3-biotin conjugate for binding to the VDBG that is immobilized on the plate. Binding of $25(\mathrm{OH})$ VD-biotin was detected by peroxidase-labeled streptavidin. Incubation was followed by a washing step to remove unbound components. The color intensity is inversely proportional to the concentration of $25(\mathrm{OH}) \mathrm{VD}$ in the sample and was measured photometrically at $450 \mathrm{~nm}$ using ELISA reader (Stat Fax 2100 Microplate Reader). Women were then categorized into 3 groups according to their serum $25(\mathrm{OH})$ VD status: 1) Deficiency of VD was defined as a $25(\mathrm{OH})$ VD level $<20 \mathrm{ng} / \mathrm{mL}(50 \mathrm{nmol} / \mathrm{L}), 2)$ Insufficiency of VD was defined as a $25(\mathrm{OH}) \mathrm{VD}$ level of 2030- $\mathrm{ng} / \mathrm{mL}$ (5075- nmol/L), 3) Sufficiency of VD was defined as a $25(\mathrm{OH}) \mathrm{VD}$ level $>30 \mathrm{ng} / \mathrm{mL}(75 \mathrm{nmol} / \mathrm{L})$.

The primary study outcome measure was the correlation between VD status and PTB, while the secondary outcome measures included the prevalence of VD deficiency in women with PTB.

The collected data was analyzed using statistical package for social sciences (IBM SPSS, version 20.0). Data was presented according to the type of data of each variable; mean and standard deviation $( \pm \mathrm{SD})$ for parametric numerical data, median and interquartile range (IQR) for non-parametric data and frequency and percentage of non-numerical data. Independent sample student t-test was used to compare means of two study groups. Chi square test and Fisher's exact test, as appropriate, were used to examine the relationship between two qualitative variables. Two tailed $p$-value $<0.05$ was considered statistically significant.

\section{RESULTS}

As it is shown in the participants' flowchart, among the 100 women who were initially recruited to participate in the study, the final statistical analysis included 40 cases in the PTB group and 40 controls in the TB group (Fig. 1).

As expected, PTB group had a statistically significant lower GA at delivery (33.651.67 \pm versus $38.331 .05 \pm$ in TB group, $p<0.001)$. VD deficiency was more prevalent in PTB group [35 (87.5\%) versus $9(22.5 \%)$ in the TB group, $p<0.001]$ while VD sufficiency and insufficiency were more prevalent in TB group. PTB group had statistically significant lower VD levels $(13.347 .71 \pm \mathrm{ng} / \mathrm{ml}$ versus $32.9118 .98 \pm \mathrm{ng} / \mathrm{ml}$ in the TB group, $p<0.001$ ) (Table 1).

There was a moderate positive linear relationship between GA at delivery and VD level (Pearson correlation $=0.571, p<0.001)$. Among the studied maternal outcomes, delivery by cesarean section was more prevalent in PTB group $(62.5 \%$ versus $30.0 \%$ in the TB group, $p=0.004$ ) (Table 2). 
Table 3 revealed and displayed that age and BMI did not show statistical significant difference between both research groups ( $p$ values $=0.904,0.58$, consecutively) whereas GA at delivery and vitamin D levels were less in the preterm research group in statistically significant fashion $(p$ value $=0.000)$.

Table 4 revealed and displayed that there was no statistical significant difference as regards parity, smoking, GDM, preeclampsia ( $p$ values $=1.000,1.000,1.000,0.692$, consecutively). However, the vaginal deliveries were much less in preterm research group and cesarean section deliveries were more in the same group in statistically significant manner $(p$ values $=0.004)$.

Table 5 revealed and displayed that GA age at delivery was statistically significantly correlated to vitamin $\mathrm{D}$ levels in which Pearson correlation $=0.571, p$ value $=0.000$.

Table 6 revealed and displayed that Vitamin D deficiency was statistically significantly more prevalent in preterm research group; while vitamin D sufficiency and insufficiency were more prevalent in full term research group in statistically significant manner $(p$ value $=0.000$ ).

Table 1 : The studied baseline parameters including vitamin D level and status

\begin{tabular}{llll}
\hline & $\begin{array}{l}\text { Preterm birth } \\
\mathrm{n}=40\end{array}$ & $\begin{array}{l}\text { Term birth } \\
\mathrm{n}=40\end{array}$ & p-value \\
Age, years & $28.47 \pm 5.56$ & $28.32 \pm 5.48$ & 0.904 \\
BMI, kg/m2 & $28.94 \pm 4.00$ & $28.48 \pm 3.55$ & 0.588 \\
GA at delivery & $33.65 \pm 1.67$ & $38.33 \pm 1.05$ & 1.000 \\
Parity $\quad$ & $10(25.0 \%)$ & $10(25.0 \%)$ & \\
1 & $10(25.0 \%)$ & $10(25.0 \%)$ & 1.000 \\
2 & $7(17.5 \%)$ & $7(17.5 \%)$ & $<0.0019$ \\
Smoking & $13(32.5 \%)$ & $3(7.5 \%)$ & $<0.0019$ \\
Vitamin D level, ng/mL & $3(7.5 \%)$ & $32.91 \pm 18.98$ & \\
Vitamin D & $13.34 \pm 7.71$ & $19(47.5 \%)$ & $12(30.0 \%)$ \\
Sufficiency & $2(5.0 \%)$ & $9(22.5 \%)$ & \\
Insufficiency & $3(7.5 \%)$ & & \\
Deficiency & $35(87.5 \%)$ & &
\end{tabular}

BMI, body mass index; GA, Gestational age; $n$, number.

Data are presented as number $(\%)$ or mean \pm standard deviation as appropriate.

I indicates statistical significance

Table 2: The studied maternal outcome measures

\begin{tabular}{|c|c|c|c|}
\hline & $\begin{array}{l}\text { Preterm birth } \\
n=40\end{array}$ & $\begin{array}{c}\text { Term birth } \\
n=40\end{array}$ & p-value \\
\hline Maternal outcome & & & \\
\hline $\begin{array}{l}\text { Diabetes mellitus } \\
\text { Preeclampsia } \\
\text { Cesarean sections }\end{array}$ & $\begin{array}{l}3(7.5 \%) \\
3(7.5 \%) \\
25(62.5 \%\end{array}$ & $\begin{array}{l}3(7.5 \%) \\
4(10.0 \%) \\
12(30.0 \%)\end{array}$ & $\begin{array}{l}1.000 \\
0.692 \\
0.0049\end{array}$ \\
\hline
\end{tabular}

Data are presented as number $(\%)$ or mean \pm standard deviation as appropriate.

II indicates statistical significance. 
Table 3: Comparison between Group I (Preterm) and Group II (Full term) as Regard Age, BMI, GA of Delivery and VD level

\begin{tabular}{|c|c|c|c|c|c|c|}
\hline & \multicolumn{4}{|c|}{ Group } & \multirow{3}{*}{$\begin{array}{l}\text { Independent } \\
\text { sample t test }\end{array}$} & \multirow{3}{*}{ P-value } \\
\hline & \multicolumn{2}{|c|}{ Pre term } & \multicolumn{2}{|c|}{ Full term } & & \\
\hline & Mean & $+\mathrm{SD}$ & Mean & $+\mathrm{SD}$ & & \\
\hline Age & 28.47 & 5.56 & 28.32 & 5.48 & 0.121 & 0.904 \\
\hline BMI & 28.94 & 4.00 & 28.48 & 3.55 & 0.544 & 0.588 \\
\hline GA of Delivery & 33.65 & 1.67 & 38.33 & 1.05 & -14.983 & $0.000 * *$ \\
\hline VD & 13.34 & 7.71 & 32.91 & 18.98 & -6.041 & $0.000 * *$ \\
\hline
\end{tabular}

P value 0.0003- 0.0007

Table 4: Comparison between Group I (Preterm) and Group II (Full term) as Regard Parity, Smoking status, GDM, Preeclampsia and Mode of Delivery.

\begin{tabular}{|c|c|c|c|c|c|c|c|}
\hline & & \multicolumn{4}{|c|}{ Group } & \multirow{3}{*}{ Chi square } & \multirow{3}{*}{$P$-value } \\
\hline \multicolumn{2}{|c|}{ Variables } & \multicolumn{2}{|c|}{ Preterm } & \multicolumn{2}{|c|}{ Full term } & & \\
\hline & & No. & $\%$ & No. & $\%$ & & \\
\hline & 0 & 10 & $25.0 \%$ & 10 & $25.0 \%$ & \multirow{5}{*}{0.000} & \multirow{5}{*}{1.000} \\
\hline \multirow{4}{*}{ Parity } & 1 & 10 & $25.0 \%$ & 10 & $25.0 \%$ & & \\
\hline & & & & & & & \\
\hline & 2 & 7 & $17.5 \%$ & 7 & $17.5 \%$ & & \\
\hline & $>3$ & 13 & $32.5 \%$ & 13 & $32.5 \%$ & & \\
\hline \multirow{3}{*}{ Smoking } & No & 37 & $92.5 \%$ & 37 & $92.5 \%$ & \multirow{3}{*}{0.000} & \multirow{3}{*}{1.000} \\
\hline & & & & & & & \\
\hline & Yes & 3 & $7.5 \%$ & 3 & $7.5 \%$ & & \\
\hline \multirow{3}{*}{ GDM } & No & 37 & $92.5 \%$ & 37 & $92.5 \%$ & \multirow{3}{*}{0.000} & \multirow{3}{*}{1.000} \\
\hline & & & & & & & \\
\hline & Yes & 3 & $7.5 \%$ & 3 & $7.5 \%$ & & \\
\hline \multirow{3}{*}{ Preeclampsia } & No & 37 & $92.5 \%$ & 36 & $90.0 \%$ & \multirow{3}{*}{$\begin{array}{c}0.157 \\
\text { FE (\#) }\end{array}$} & \multirow{3}{*}{0.692} \\
\hline & & & & & & & \\
\hline & Yes & 3 & $7.5 \%$ & 4 & $10.0 \%$ & & \\
\hline \multirow{2}{*}{$\begin{array}{l}\text { Mode of } \\
\text { delivery }\end{array}$} & Vaginal & 15 & $37.5 \%$ & 28 & $70.0 \%$ & \multirow[b]{2}{*}{8.498} & \multirow[b]{2}{*}{$0.004^{* *}$} \\
\hline & Cs & 25 & $62.5 \%$ & 12 & $30.0 \%$ & & \\
\hline
\end{tabular}


Table 5: Correlation between GA at Delivery and VD level

\section{Vit D level}

GA at Delivery

Pearson Correlation

.571
Sig. (2-tailed)

$.000^{* *}$

P value 0.0006

Table 6: Prevalence of Vitamin D deficiency and insufficiency in Group I (Preterm) and Group II (Full-term)

\begin{tabular}{|c|c|c|c|c|c|c|}
\hline \multirow{3}{*}{ Vit. D categories } & \multicolumn{4}{|c|}{ Group } & \multirow{3}{*}{ Chi square test } & \multirow{3}{*}{ P-value } \\
\hline & \multicolumn{2}{|c|}{ Preterm } & \multicolumn{2}{|c|}{ Full term } & & \\
\hline & No. & $\%$ & No. & $\%$ & & \\
\hline Sufficiency & 2 & $5.0 \%$ & 19 & $47.5 \%$ & & \\
\hline Insufficiency & 3 & $7.5 \%$ & 12 & $30.0 \%$ & 34.526 & $0.000 * *$ \\
\hline Deficiency & 35 & $87.5 \%$ & 9 & $22.5 \%$ & & \\
\hline
\end{tabular}

P value : 0.0002 


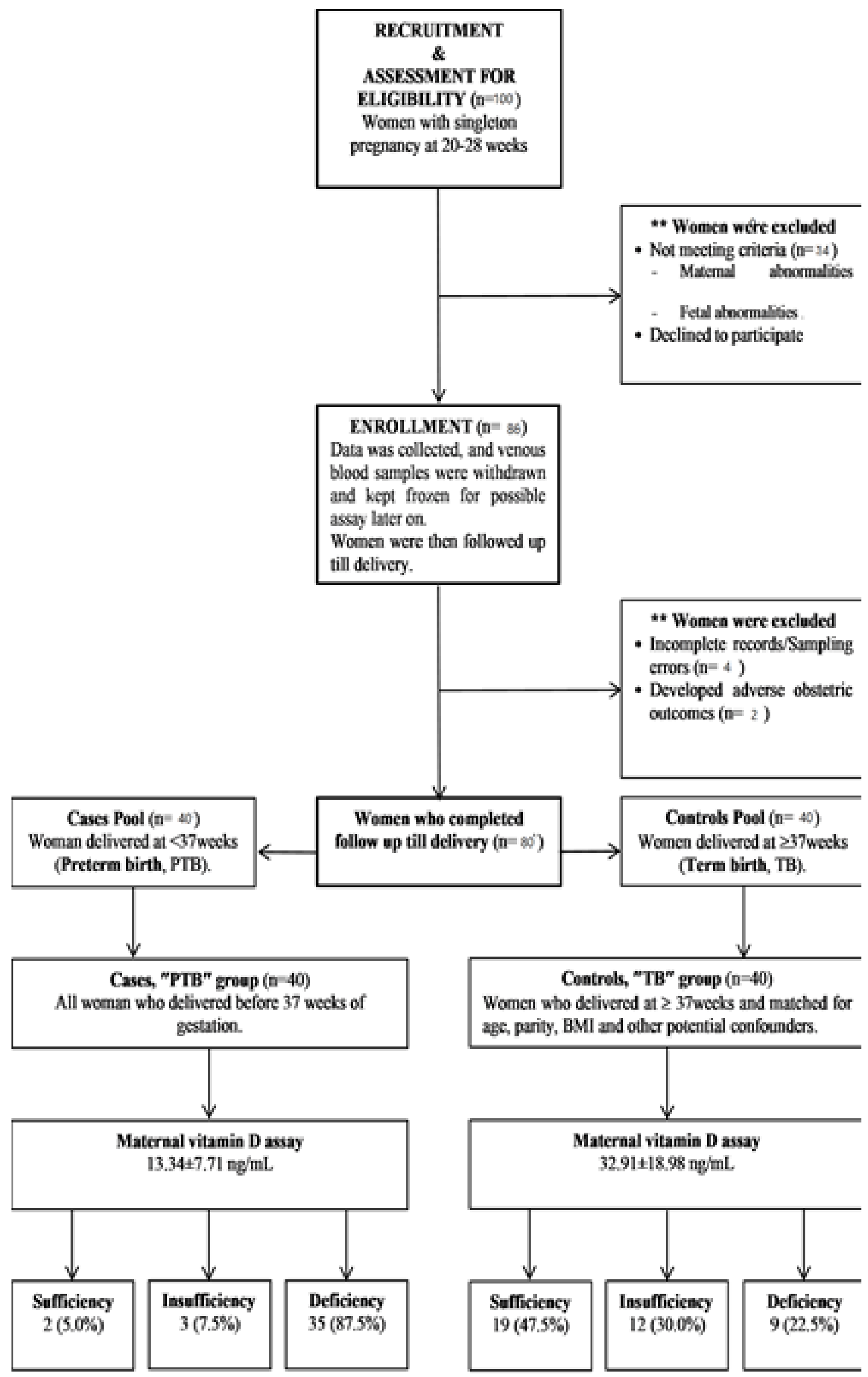

Fig.1: Participants' flowchart 


\section{DISCUSSION}

The current study reported an important association between PTB and VD deficiency, with moderate positive correlation between GA age at delivery and VD levels.

VD has been discovered 100 years ago, but it is still one of the most controversial subjects till now. Recently VD has been discovered to be implicated in diverse physiologic processes including vascular health, immunity, metabolic functions, and placental physiology. Regarding, the effect of VD on female reproduction, available data suggests an association between VD deficiency and endometriosis, polycystic ovary syndrome, impaired fertility, gestational diabetes mellitus, PTB, preeclampsia, and bacterial vaginosis. ${ }^{[18]}$

There is scientific evidence that low levels of VD are common in pregnant women. Meta-analysis of observational studies showed a positive association between VD deficiency and some adverse pregnancy outcomes including preeclampsia, PTB, small for gestational age, infectious disease cesarean section, and gestational diabetes mellitus. Interventional studies demonstrated VD intake during pregnancy could optimize the maternal as well as the neonatal VD status. Twenty-four studies were included in this meta-analysis, pregnant women with low $25 \mathrm{OH}$ VD levels $(<50 \mathrm{nmol} / \mathrm{l})$ had increased risk of preeclampsia $(\mathrm{OR}=2.09,95 \% \mathrm{CI}=1.50-2.90)$, gestational diabetes mellitus $\quad(\mathrm{OR}=1.38, \quad 95 \% \quad \mathrm{CI}=1.12-1.70), \quad \mathrm{PTB}$ $(\mathrm{OR}=1.58, \quad 95 \% \quad \mathrm{CI}=1.08-2.31)$ and small for gestational age $(\mathrm{OR}=1.52,95 \% \mathrm{CI}=1.08-2.15)^{[19,20]}$. Cesarean section rate was significantly higher in PTB group, this was mainly related to the higher incidence of abnormal fetal presentation among this group, and another possible explanation for the higher risk of delivery by caesarean section in women with gestational VD deficiency may be due to reduced pelvic muscle strength and prolonged labor. ${ }^{[21]}$

There is a disagreement among researchers about the association between PTB and VD deficiency during pregnancy. A recent meta-analysis (10 studies including 10,098 women) showed that gestational VD deficiency ( $\mathrm{VD}<20 \mathrm{ng} / \mathrm{mL}$ ) significantly increased the risk of $\mathrm{PTB}(\mathrm{OR}=1.29,95 \% \mathrm{CI}=1.16-1.45)$ with low heterogeneity ${ }^{[22]}$. Another recent meta-analysis of six RCTs and 18 observational studies reported an association between low maternal 25 $(\mathrm{OH}) \quad \mathrm{VD}$ levels and increased risk of PTB ( $R R=0.57,95 \% \mathrm{CI}=0.36-0.91)$, it also reported that VD intake during pregnancy decreased the risk of $\mathrm{PTB}^{[23]}$.
On the contrary, some observations regarding the relationship between VD and PTB are still inconsistent. One study showed that only severe VD deficiency $(<10 \mathrm{ng} / \mathrm{ml})$ increases the risk of PTB and this association was not significant in the multivariate analysis $(\mathrm{OR}=2.47,95 \% \mathrm{CI}=0.86-7.15, p=0.094)^{[24,25]}$. Another prospective nested case control study utilized a multivariate analysis, to adjust for the potential confounders, and did not find any evidence of increased risk of PTB in relation to decreased VD levels during pregnancy ${ }^{[16]}$. In a third study, including 60 Thai pregnant women, maternal VD concentrations were not significantly different between the PTB and TB groups (20.98.4 \pm versus 21.26.7 $\pm \mathrm{ng} /$ $\mathrm{ml}$, respectively, $P=0.91)^{[15]}$. In a fourth study, maternal VD level $<30 \mathrm{nmol} / \mathrm{L}$ at 20 gestational weeks was associated increased risk of PTB among non-white mothers, but not among white mothers ${ }^{[26]}$. The findings of these studies contradict with the current research however that could be justified by the different sample size and populations.

Influent factors of gestational VD deficiency have been investigated among 3598 pregnant women, in Chinese population, 941 women had sufficient serum VD concentrations, while 1260 women had insufficient concentrations, and 1397 women had deficient concentrations. Gestational VD deficiency was more prevalent in winter; underweight women were at greater risk, while use of multivitamin preparations significantly reduced the risk of gestational VD deficiency. ${ }^{[27]}$

One of the potential points of criticism for the present study is the small sample size, to overcome this limitation, the authors have examined a large cohort of women, then adopted the nested case control design with strict matching to avoid any confounders. Based on the current findings as well as those of the previous studies, routine measurement of maternal serum VD can be advised to become an integral part of the antenatal care protocol. VD supplementation can be subsequently added to carefully selected groups to decrease the risk of PTB.

We are in bad need of conducting a large well designed multicenter RCT to determine the efficacy and safety of VD intake to reduce the risk of PTB and other adverse pregnancy outcomes, among pregnant women with VD deficiency.

Finally, it can be concluded that gestational VD deficiency is associated with increased risk of PTB and delivery by cesarean section. 


\section{CONFLICT OF INTEREST}

There are no conflict of interests.

\section{REFERENCES}

1. Fernandes SF, Chandra S. A study of risk factors for preterm labour. International Journal of Reproduction, Contraception, Obstetrics and Gynecology; Vol 4, No 5 (2015): September-October 2015 DO - 10 18203-2320/ 1770 ijrcog201507012017 Feb 10.

2. American College of Obstetricians and Gynecologists. Practice Bulletin No. 171: Management of Preterm Labor. Obstet Gynecol 2016 Oct;128(4):e155-e164.

3. Sangkomkamhang US, Lumbiganon $P$, Prasertcharoensuk W, Laopaiboon M. Antenatal lower genital tract infection screening and treatment programs for preventing preterm delivery. Cochrane Database Syst Rev 2015 Feb 1;(2):CD006178.

4. Patel PK, Pitre DS, Bhooker SP. PREDICTIVE VALUE OF VARIOUS RISK FACTORS FOR PRETERM LABOR. Community Med 2015;6(1):121-5.

5. Manios $\mathrm{Y}$, Moschonis $\mathrm{G}$, Lambrinou $\mathrm{CP}$, Tsoutsoulopoulou K, Binou P, Karachaliou A, et al. A systematic review of vitamin D status in southern European countries. Eur J Nutr 2018 Sep;57(6):2001-36.

6. Luk J, Torrealday S, Neal PG, Pal L. Relevance of vitamin D in reproduction. Hum Reprod 2012 Oct;27(10):3015-27.

7. Lerchbaum E, Obermayer-Pietsch B. Vitamin D and fertility: a systematic review. Eur J Endocrinol 2012 May;166(5):765-78.

8. Shah D, Gupta P. Vitamin D Deficiency: Is The Pandemic for Real? Indian J Community Med 2015 Oct;40(4):215-7.

9. Man RE, Li LJ, Cheng CY, Wong TY, Lamoureux E, Sabanayagam C. Prevalence and Determinants of Suboptimal Vitamin D Levels in a Multiethnic Asian Population. Nutrients 2017 Mar 22;9(3).

10. Adams JS, Hewison M. Update in vitamin D. J Clin Endocrinol Metab 2010 Feb;95(2):471-8.
11. Eggemoen AR, Falk RS, Knutsen KV, Lagerlov $\mathrm{P}$, Sletner L, Birkeland KI, et al. Vitamin D deficiency and supplementation in pregnancy in a multiethnic population-based cohort. BMC Pregnancy Childbirth 2016 Jan 19;16:7.

12. Liu NQ, Kaplan AT, Lagishetty V, Ouyang YB, Ouyang Y, Simmons CF, et al. Vitamin D and the regulation of placental inflammation. J Immunol 2011 May 15;186(10):596874-.

13. Bodnar LM, Platt RW, Simhan HN. Earlypregnancy vitamin D deficiency and risk of preterm birth subtypes. Obstet Gynecol 2015 Feb;125(2):439-47.

14. McDonnell SL, Baggerly KA, Baggerly CA, Aliano JL, French CB, Baggerly LL, et al. Maternal $25(\mathrm{OH}) \mathrm{D}$ concentrations $>/=40 \mathrm{ng} / \mathrm{mL}$ associated with $60 \%$ lower preterm birth risk among general obstetrical patients at an urban medical center PLoS One 2017;12(7):e0180483.

15. Bhupornvivat N, Phupong V. Serum 25-hydroxyvitamin $\mathrm{D}$ in pregnant women during preterm labor. Asia Pac J Clin Nutr 2017 Mar;26(2):287-90.

16. Yang L, Pan S, Zhou Y, Wang X, Qin A, Huang $\mathrm{Y}$, et al. The Correlation Between Serum Vitamin D Deficiency and Preterm Birth. Med Sci Monit 2016 Nov 16;22:4401-5.

17. Bozoklu AO, Sancakdar E, Karakus S, Yildiz C, Akkar I, Arslan M, et al. Evaluation of Maternal Serum 25-Hydroxyvitamin D, Paraoxonase 1 Levels, and Neutrophil-to-Lymphocyte Ratio in Spontaneous Preterm Birth. Med Sci Monit 2016 Apr 13;22:1238-43.

18. Triunfo S, Lanzone A. Potential impact of maternal vitamin D status on obstetric well-being. J Endocrinol Invest 2016 Jan;39(1):37-44.

19. Wei SQ. Vitamin D and pregnancy outcomes. Curr Opin Obstet Gynecol 2014 Dec;26(6):438-47.

20. Wei SQ, Qi HP, Luo ZC, Fraser WD. Maternal vitamin $\mathrm{D}$ status and adverse pregnancy outcomes: a systematic review and meta-analysis. J Matern Fetal Neonatal Med 2013 Jun;26(9):889-99.

21. Scholl TO, Chen X, Stein P. Maternal vitamin D status and delivery by cesarean. Nutrients 2012 Apr;4(4):319-30. 
22. Qin LL, Lu FG, Yang SH, Xu HL, Luo BA. Does Maternal Vitamin D Deficiency Increase the Risk of Preterm Birth: A Meta-Analysis of Observational Studies. Nutrients 2016 May 20;8(5).

23. Zhou SS, Tao YH, Huang K, Zhu BB, Tao FB. Vitamin D and risk of preterm birth: Up-to-date meta-analysis of randomized controlled trials and observational studies. J Obstet Gynaecol Res 2017 Feb;43(2):247-56.

24. Baczynska-Strzecha M, Kalinka J. Assessment of correlation between vitamin $\mathrm{D}$ level and prevalence of preterm births in the population of pregnant women in Poland. Int J Occup Med Environ Health 2017 Oct 6;30(6):933-41.
25. Morley R, Carlin JB, Pasco JA, Wark JD. Maternal 25-hydroxyvitamin $\mathrm{D}$ and parathyroid hormone concentrations and offspring birth size. J Clin Endocrinol Metab 2006 Mar;91(3):906-12.

26. Bodnar LM, Klebanoff MA, Gernand AD, Platt RW, Parks WT, Catov JM, et al. Maternal vitamin $\mathrm{D}$ status and spontaneous preterm birth by placental histology in the US Collaborative Perinatal Project. Am J Epidemiol 2014 Jan $15 ; 179(2): 168-76$.

27. Chen YH, Fu L, Hao JH, Wang H, Zhang C, Tao $\mathrm{FB}$, et al. Influent factors of gestational vitamin D deficiency and its relation to an increased risk of preterm delivery in Chinese population. Sci Rep 2018 Feb 26;8(1):3608. 